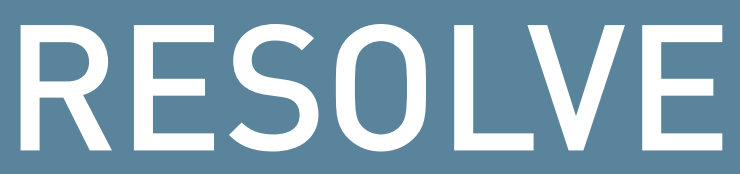

N E T W O R K

\section{FACT/SHEET}

LAKE CHAD BASIN

RESEARCH SERIES

\title{
Religious Politics and Student Associations in Nigeria
}

This fact sheet provides a snapshot of conclusions from RESOLVE's 2017-2019 Lake Chad Basin Research Initiative. The project assesses the role of the state, civil society, and other non-state actors in shaping the political divides over the role of religion in education and community and state responses to extremism in Chad, Nigeria, and Cameroon. Given the youthful base of Boko Haram and other violent extremist movements, policymakers have asked whether universities might either incubate or counter extremism. Discussions with stakeholders and a critical review of the literature revealed a need to test prevailing assumptions about the relationship between education, religion, and violent extremism. To learn more about the research methodology and detailed findings, please refer to the RESOLVE Research Brief by Abdoulaye Sounaye and Medinat Abdulazeez Malefakis: Religious Politics and Student Associations in Nigeria.

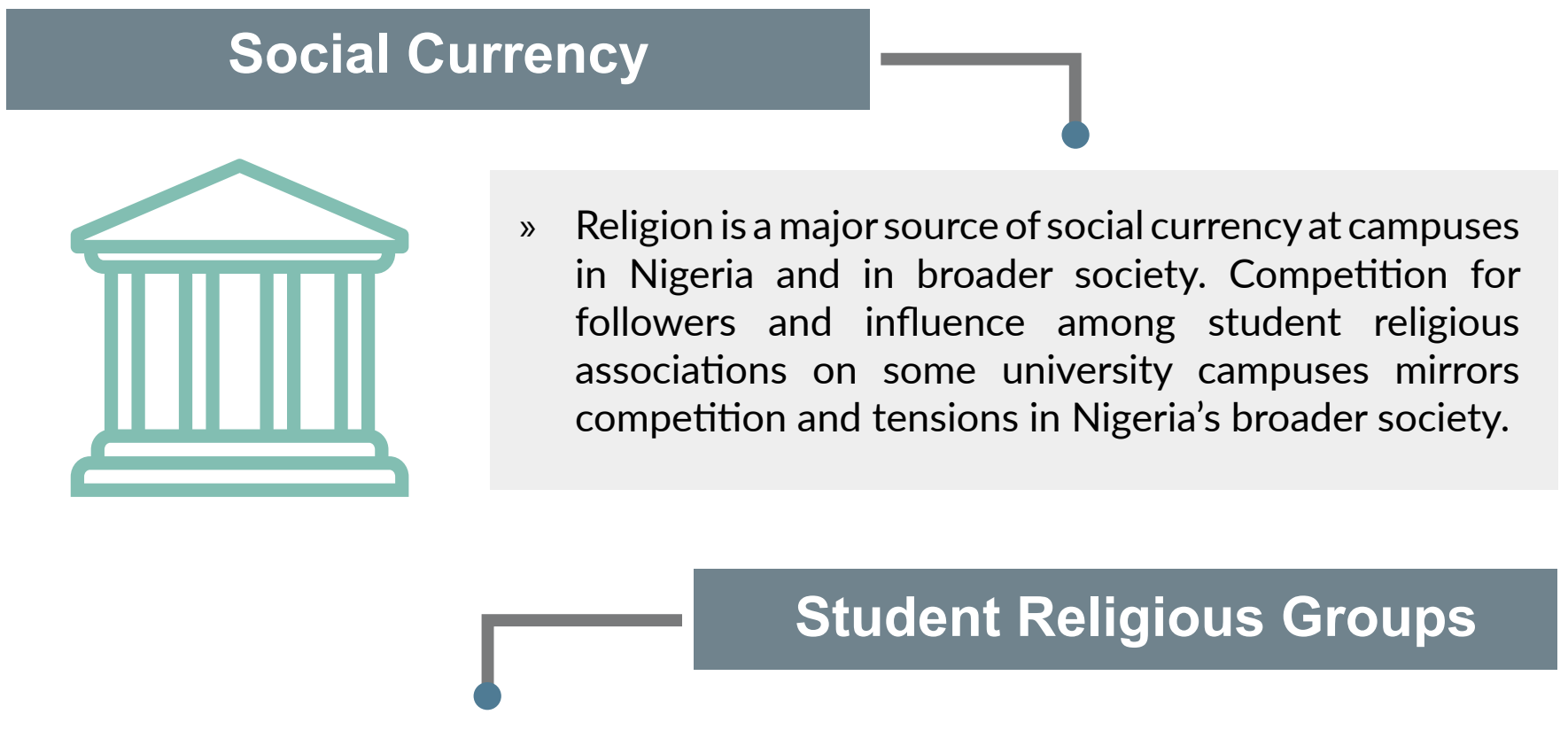

" Both Muslim and Christian student religious groups offer support for students during their careers, influence resources on campus, and facilitate connections to influential actors. Groups' influence make them potential actors to foster broader community resilience and harmony on and off campus.
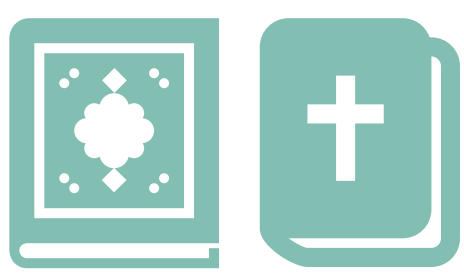


\section{Little Evidence of VE}

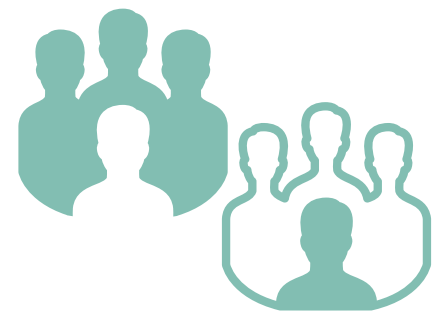

» There is little evidence of violent extremism at Nigerian higher education institutions examined. However, uneven power dynamics and growing grievances among student groups can fuel religious divides.

\section{Religious Divides}

» University policies on the representation of religious groups and ongoing interreligious and intrareligious divides can further competition, polarization, and violence among different religious student populations, exacerbated by university policies that grant authority to select religious student associations over others.

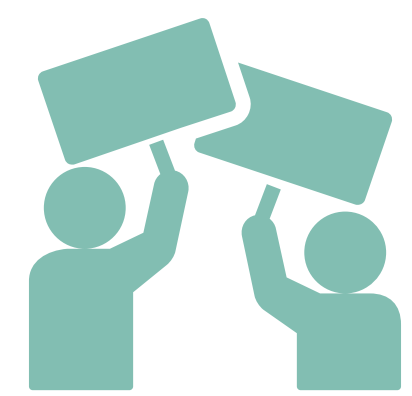

\section{Key Takeaways}

» Support for organic activities to increase dialogue and discussion on campus could help to bridge divides between student groups and address vulnerabilities that might be exploited by violent extremists and others.

» Policy and practice should work with university administrators and student groups to develop and implement non-exclusionary policies for the regulation of religious resources and affairs on campuses. Treat students as key partners in any such expansion and include their voices in the process.

» Interventions should support and engage religious and non-religious student groups as partners in shared P/CVE and conflict resolution initiatives, particularly those to promote unity on and off campus. Expanded participation can help to unite disparate student religious populations around a common cause and foster a sense of community and resiliency.

\section{RESOLVE Network}

better research.informed practice.improved policy on violent extremism.

UNITED STATES

Institute of Peace Making Peace Possible 